NACHRICHTEN

\section{Contributions wanted: WISIONS: a new website on energy and resource efficient projects world-wide}

WISIONS is a new initiative of the Wuppertal Institute for Climate, Environment and Energy, carried out with the support of the Swiss-based foundation ProEvolution to foster practical sustainable energy and resource efficiency projects.

\section{http://www.wisions.net}

The objective is to combine spreading knowledge about existing successful projects with progressing the realisation of new project ideas.

Two fields of action will be addressed: SEPS and PREP.

SEPS, the Sustainable Energy Project Support, aims at identifying promising project ideas on a world-wide scale and seeks to overcome the existing barriers by providing technical and other support. The projects have to be in a stage prior to implementation and will be judged according to a set of ambitious criteria and the quality of a consistent implementation strategy.

PREP, the Promotion of Resource Efficiency Projects, has the key objectives of publishing and promoting good practice in energy and resource efficiency. People around the world are asked to present their "good practice examples". The topic and the target groups thus will vary regularly with the objective of addressing a wide range of issues and stakeholders. Right now the first topic "resourceefficiency in the construction sector" with its main emphasis on the efficient use of energy and renewables is starting.

The most convincing projects will be promoted to multipliers, political decisionmakers, scientists and activists. By doing this, they will get the publicity they deserve and provide certain ideas worldwide to improve the efficient use of resources.

Everybody with knowledge and experience in renewable energy, energy or resource efficiency, could be helpful in bringing new ideas into action: a promising project concept in renewable energy or energy efficiency and good practice examples that could sample for other projects and regions.

For more information about WISIONS' background, current topics, selection criteria, application rules, and initiative's progress, please visit the website at the address given above. 